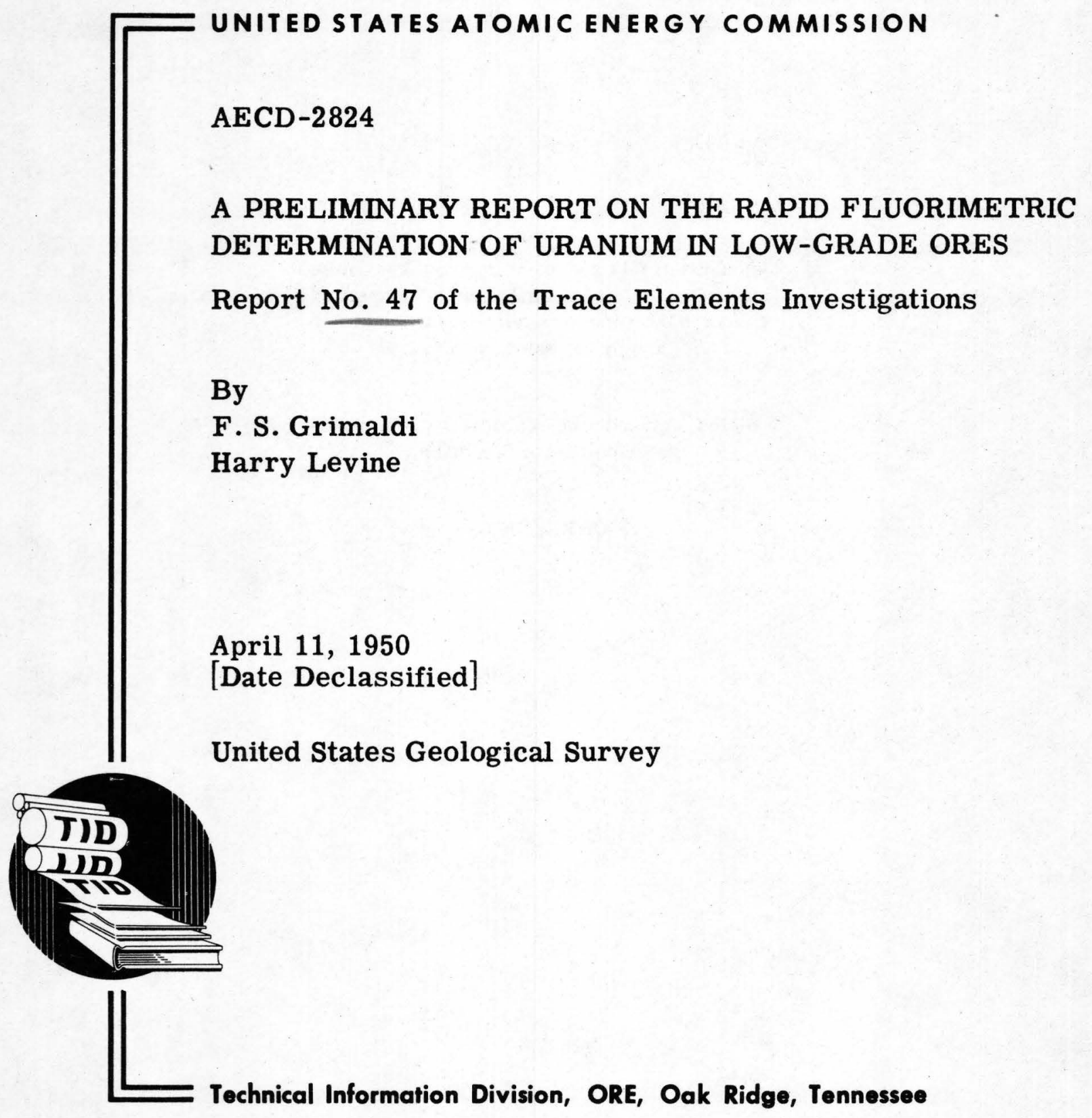


Issuance of this document does not constitute authority for declassification of classified copies of the same or similar content and title and by the same authors.

Styled, retyped, and reproduced from copy as submitted to this office.

PRINTED IN USA

PRICE 5 CENTS 


\title{
A PRELIMINARY REPORT ON THE RAPID FLUORIMETRIC DETERMINATION OF URANIUM IN LOW-GRADE ORES
}

\author{
Report No. 47 of the Trace Elements Investigations
}

By F. S. Grimaldi and Harry Levine

\begin{abstract}
A simple and very rapid fluorimetric procedure is described for the determination of uranium in low-grade shale and phosphate ores. The best working range is from 0.001 per cent to about 0.04 per cent $\mathrm{U}$. The procedure employs batch extraction of uranium nitrate by ethyl acetate, using aluminum nitrate as the salting agent, prior to the visual fluorimetric estimation. The procedure is especially designed to save reagents; only $9.5 \mathrm{~g}$ of aluminum nitrate and $10 \mathrm{ml}$ of ethyl acetate being used for one analysis. The solution of the sample by means of a fusion with $\mathrm{NaOH}-\mathrm{NaNO}_{3}$ flux is rapid. After fusion the sample is immediately extracted without removing silica and other hydrolytic precipitates. Aluminum nitrate very effectively ties up fluoride and phosphate, thus eliminating steps required for their removal.
\end{abstract}

\section{INTRODUCTION}

The exceedingly sensitive fluorescence of uranium-fluoride phosphors under ultraviolet light has been extensively used in the project for the quantitative estimation of uranium in a variety of materials. Unfortunately, many elements interfere seriously by quenching the fluorescence. For example, as little as $10 \mu \mathrm{g}$ of iron reduces the fluorescence of a sample of uranium by about 10 per cent. In general the critical factor in the quenching phenomenon is the concentration of the quenching element in the flux, and not the ratio of quencher to uranium.

Two procedures have appeared in the project literature that eliminate the interferences mentioned. One developed by Price and co-workers ${ }^{1}$ employs a dilution technique which depends on reducing the quenching to a negligible factor by using a sufficiently small sample for the analysis. Since the intensity of the fluorescence of the small sample required by the procedure is weak, a more elaborate apparatus employing photomultiplier tubes is needed. Also in this range the possibility of contamination by dust in the air is great, so that accessory equipment is needed to condition the air.

The second procedure involves the chemical separation of uranium from interfering elements prior to estimation by the fluorescence method. Accepted procedure for this separation involves the extraction of uranium nitrate with organic solvents after the addition of a salting agent. The distribution of uranium nitrate depends both on the solvent employed and the salting agent selected, and for this reason a particular procedure may lend itself to either batch or continuous extraction. For example, with ammonium nitrate as the salting agent and ether as the solvent, continuous extraction is recommended. The procedure of Grimes, using ammonium nitrate and penta-ether, is a batch extraction. Furman et al 2 have studied many salting agents and have shown that batch extraction with ordinary ether is feasible when calcium nitrate is the salting agent. Ammonium nitrate is the preferred salting agent in fluorescent work because any of the agent which accompanies uranium in the extraction is easily removed. Other salting agents may extract sufficiently to cause partial quenching. The procedures in the project are all inadequate in one or more of these respects: 
1. The solution of the sample is unnecessarily long.

2. Special and expensive solvents are employed.

3. Large amounts of reagents are needed.

We undertook this research to improve the procedure with respect to the three points mentioned above. The final procedure adopted is very simple and rapid. We employ a batch extraction using aluminum nitrate as the salting agent and ethyl acetate as the solvent. Aluminum nitrate was selected because moderate amounts of aluminum (about $50 \mathrm{mg}$ ) had been shown to have no quenching action on the uranium-fluoride phosphors. Also aluminum very effectively ties up phosphate and fluoride, elements that normally interfere with extraction procedures. Ethyl acetate was chosen as the solvent because it is readily available and presents no such hazards as work with ether entails. At first it was thought that the ethyl acetate might hydrolyze to some extent and that the acetate formed could conceivably complex the uranium and prevent its complete extraction. However, as used in the procedure, very little if any ethyl acetate hydrolyzes and no interference was ever noted. It is doubtful, however, whether ethyl acetate can be used for continuous extractions. The amounts of ethyl acetate and aluminum nitrate used for the extraction are respectively $10 \mathrm{ml}$ and $9.5 \mathrm{~g}$.

\section{BRIEF OUTLINE OF PROCEDURE AND DISCUSSION}

The sample $(0.15 \mathrm{~g})$ is completely decomposed by fusion with $\mathrm{NaOH}-\mathrm{NaNO}_{3}$ mixture. This flux will decompose shales and phosphate rocks. After fusion, the melt is leached with water and acidified with nitric acid and $7.5 \mathrm{ml}$ of nitric acid is added in excess. Silica does not separate out if the acid is added to the cool solution. If any hydrolytic precipitate forms, no matter what it is, it is not filtered off. The solution is then made up to $50 \mathrm{ml}$ and a $5-\mathrm{ml}$ aliquot is transferred to a test tube. To this is added $9.5 \mathrm{~g}$ of aluminum nitrate (which is enough to saturate $5 \mathrm{ml}$ of solution), and from a pipette $10 \mathrm{ml}$ of ethyl acetate is added and the mixture shaken for $30 \mathrm{sec}$. After the layers have separated, about $8 \mathrm{ml}$ of the ethyl acetate layer is drawn off and filtered through a dry filter paper. Five milliliters of the filtered ethyl acetate is removed by pipette, transferred to a clean platinum crucible, and evaporated off. Then the fluoride flux is added to the crucible and the flux is melted for a prescribed time. After cooling, the fluorescence is compared against a series of standards also contained in platinum crucibles. The standards are prepared from standard amounts of uranium transferred to platinum crucibles and heated with the fluoride flux in the same manner and for the same length of time as for the samples. Since it has been found necessary to play the melt around the sides of the crucible in order to bring the flux in contact with any of the sample that may have crept up during the evaporation, it is preferable to prepare the standards in the same manner. Proper heating is an important factor in the results obtained. Too much heating, especially at an elevated temperature, may dissolve some platinum, which causes quenching; too little heating may also give low results because insufficient time has been allowed to incorporate the sample into the flux. With a little experience, the proper method of heating is easily determined. It is good practice for each operator to make his own sets of standards.

Three grams of the fluoride flux is used for the analysis. This amount is unnecessarily large. At the time of this work gold discs were not available; when they arrive, it is planned to work with discs utilizing $0.3 \mathrm{~g}$ of the flux and one-tenth the amount of the sample used with the platinum crucible method. Use of a fluorimeter, when one is available, will eliminate visual interpolation between standards.

The fluoride flux used in the procedure is the excellent flux developed by Coleman and Grimes, ${ }^{3}$ consisting of 9 per cent $\mathrm{NaF}-91$ per cent $\mathrm{NaKCO}_{3}$. Standards made by the use of this flux keep well in a desiccator but should be checked weekly.

The extraction of uranium nitrate by $10 \mathrm{ml}$ of ethyl acetate according to the procedure has been found quantitative for $0.15,0.3,0.45,0.60$, and $0.75 \mu \mathrm{g}$, for 0.3 and $5 \mathrm{mg}$ uranium, and very nearly so for $25 \mathrm{mg}$ of uranium after a single 30 -sec shaking. The distribution of a few elements likely to extract is given in the section Experiments I. About 60 per cent of the thorium is extracted. The extraction of the other elements is much less than that obtained with other solvents and salting agents. This may be due to the fact that the organic solvent is filtered before being analyzed for the element. It is of interest to note that vanadium is not extracted to any extent. 
The results of the analyses of a placer sample and a shale (Table 1) using aluminum nitrate and ethyl acetate and colorimetric instead of fluorimetric estimation show the feasibility of batch extraction for colorimetric amounts.

A blank should be run on each bottle of aluminum nitrate to be used in the analysis. If the aluminum nitrate is found to contain uranium, it may be purified by batch extraction with ether using the propor tions $9.5 \mathrm{~g}$ of $\mathrm{Al}\left(\mathrm{NO}_{3}\right)_{3} \cdot 9 \mathrm{H}_{2} \mathrm{O}, 5 \mathrm{ml}$ of 15 per cent $\mathrm{HNO}_{3}$ and $10 \mathrm{ml}$ ether and allowing the nitrate to crystallize at room temperature.

\section{GENERAL PROCEDURE}

The procedure is based on eventually using $7.5 \mathrm{mg}$ samples for ores in the range 0.001 to 0.01 per cent uranium. For higher ranges a proportionally smaller aliquot is taken.

1. Grid about $2 \mathrm{~g}$ of 40 to 80 mesh sample in an agate mortar to a fine powder to insure that a representative sample will be taken for analysis.

2. Weigh $0.15 \mathrm{~g}$ of the sample and transfer it to a $25 \mathrm{ml}$ clean iron crucible. Roast if organic matter is present.

3. Add $1.5 \mathrm{~g}$ of $\mathrm{NaOH}$ (15 pellets) and about $0.1 \mathrm{~g} \mathrm{NaNO}_{3}$ and fuse at a low red heat. The heating should not be prolonged nor at too high a temperature for silicate and phosphate rock.

4. Allow the melt to cool. Add $15 \mathrm{ml}$ of water and heat on the steam bath for a few seconds to disintegrate the melt.

5. Transfer the solution to a $100-\mathrm{ml}$ beaker, scrubbing the crucible thoroughly.

6. Allow the solution to cool to about $30^{\circ} \mathrm{C}$. Add $\mathrm{HNO}_{3}$ drop by drop to neutrality and then $7.5 \mathrm{ml}$ in excess. Any hydrolytic precipitate is not filtered off.

7. Bring the solution just to boiling to dissolve whatever will go into solution by this treatment. Cool.

8. Transfer the solution to a $50-\mathrm{ml}$ volumetric flask. Make to mark and remove a $5-\mathrm{ml}$ aliquot by pipette. Transfer this to a $30-\mathrm{ml}$ test tube.

9. Add $9.5 \mathrm{~g}$ of $\mathrm{Al}\left(\mathrm{NO}_{3}\right)_{3} \cdot 9 \mathrm{H}_{2} \mathrm{O}$ and dissolve the salt by warming the sample over a flame. Shake the solution a few times to obtain homogeneity. Cool under the tap.

10. Add $10 \mathrm{ml}$ of ethyl acetate from a pipette, stopper the tube and shake for at least $30 \mathrm{sec}$. Remove the stopper and then fit it very loosely and allow the layers to separate for about $5 \mathrm{~min}$.

11. Draw off about $8 \mathrm{ml}$ of ethyl acetate by means of a pipette and filter this through a dry filter using a $5.5-\mathrm{cm}$ or smaller filter paper to minimize evaporation. Collect the filtrate in a clean dry beaker.

12. Transfer by means of a clean dry pipette $5 \mathrm{ml}$ of the filtered ethyl acetate to a clean $25-\mathrm{ml}$ platinum crucible.

13. Evaporate off the ethyl acetate slowly. This is the critical step as ethyl acetate is very volatile and may evaporate in a flash, with a consequent loss of uranium. The best method of evaporation may be with infrared lamps, but we have not tried it.

14. Ignite the residue. Add $3 \mathrm{~g}$ of the fluoride flux ( 9 per cent $\mathrm{NaF}-91$ per cent $\mathrm{NaKCO}_{3}$ mixture), and heat. After the flux melts, heat for a prescribed length of time (about $2 \mathrm{~min}$ ), playing the melt around the sides of the crucible to absorb any sample that crept up during the evaporation. The temperature should be kept at about $750^{\circ} \mathrm{C}$. Set the crucible down and allow the melt to cool and solidify.

15. View under ultraviolet light and match the fluorescence against a series of standards made to correspond to 0.000 per cent, 0.002 per cent, 0.004 per cent, 0.006 per cent, 0.008 per cent, and 0.010 per cent uranium based on a $7.5-\mathrm{mg}$ sample. These contain respectively $0.00,0.15,0.30,0.45,0.60$, and $0.75 \mu \mathrm{g}$ of uranium in $3 \mathrm{~g}$ of flux. If all the uranium from the sides of the crucible was not absorbed by the disc, low results would be obtained. However, if the ultraviolet light is directed to the sides of the crucible this is made evident by patches of fluorescence much more brilliant than the main mass. When this occurs the heating should be repeated. We have found it good practice to repeat the heating and matching as a matter of routine. We have been using for the source of ultraviolet light the 110-volt, 60cycle Mineralight lamp, manufactured by the Ultraviolet Products, Inc., Los Angeles, California. This is a cold quartz mercury lamp, 90 per cent of whose radiation is in the $2537 \mathrm{~A}$ mercury line. The Corning red purple Corex filter No. 9863 is a good filter to transmit the ultraviolet and absorb the visible. Ultraviolet radiation may be dangerous to the eyes. Goggles transmitting 5200 to $6400 \mathrm{~A}$ radiation should be worn when visual comparison is made. 


\section{ANALYTICAL RESULTS}

The samples were analyzed by the United States Geological Survey cupferron-colorimetric procedure and by the fluorescence procedure of this paper. Two samples were also analyzed colorimetrically using the batch extraction of uranium with aluminum nitrate as the salting agent and ethyl acetate as the solvent. The results are shown in Table 1 .

Table 2 gives the results of analyses of a series of samples of shales and phosphates whose uranium content was not known to the two analysts. Samples of shales and phosphates had been analyzed by the United States Geological Survey cupferron colorimetric method. The samples for analysis were made up of weighed and carefully mixed portions of these analyzed samples.

\section{EXPERIMENT I. EXTRACTION BEHAVIOR OF SOME ELEMENTS}

To $5 \mathrm{ml}$ of a 15 per cent nitric acid solution containing the nitrate of the element under test, $9.5 \mathrm{~g}$ of $\mathrm{Al}\left(\mathrm{NO}_{3}\right)_{3} \cdot 9 \mathrm{H}_{2} \mathrm{O}$ was added and shaken $30 \mathrm{sec}$ with $10 \mathrm{ml}$ of ethyl acetate. The ethyl acetate layer was drawn off and filtered and then tested quantitatively for the particular element. The results are given in Table 3.

\section{REFERENCES}

1. G. R. Price, R. J. Ferretti, and S. Schwartz, The Micro-Fluorimetric Determination of Uranium, Met. Lab. CC-2985, June 1945.

2. N. H. Furman, R. J. Mundy, and G. H. Morrison, The Distribution of Uranyl Nitrate from Aqueous Solutions to Diethyl Ether, Princeton ACMP Coll. Paper 50, May 1946.

3. C. F. Coleman and W. R. Grimes, Fluorescence Methods, Tennessee Eastman Corporation, C-4.100.30, June 1946 .

Table 1

$\begin{array}{cccc} & \text { Cupferron- } & \text { Colorimetric } & \\ \text { colorimetric } & \text { extraction } & \text { Fluorimetric } \\ \text { Sample } & \text { U, } \% & \text { U, } \% & \text { U, } \%\end{array}$

Phosphate rock
Phosphate rock
Phosphate rock
Phosphate rock
Phosphate rock
Silicate containing fluorite
Shale
Shale
Shale
Shale
Shale
Shale
Shale
Shale
Placer*
Zircon concentrate
Zircon concentrate
Monazite*
Monazite

0.012

0.012

0.023

0.022

0.022

0.023

0.011

0.011

0.017

0.016

0.032

0.032

0.0075

0.007

0.0055

0.005

$0.002 \quad 0.002$

$\begin{array}{ll}0.007 & 0.007\end{array}$

$0.007 \quad 0.007$

$\begin{array}{ll}0.0025 & 0.002\end{array}$

0.008

0.008

0.009

0.009

0.009

0.12

0.12

0.1

0.019

0.02

0.09

0.09

0.19

0.2

0.025

0.024

*It is not recommended that uranium be determined fluorimetrically with samples containing such high percentages of uranium since more precise results will be obtained colorimetrically. The results are nevertheless interesting and useful for a quick estimate. 


\section{Table 2}

$\begin{array}{cccc}\text { Sample } & \begin{array}{c}\text { Analyst A } \\ \text { U, \% }\end{array} & \begin{array}{c}\text { Analyst B } \\ \text { U, \% }\end{array} & \begin{array}{c}\text { From cupferron colorimetric } \\ \text { U, \% }\end{array} \\ & & & \\ 1 & 0.015 & 0.015 & 0.012 \\ 2 & 0.017 & 0.015 & 0.014 \\ 3 & 0.022 & 0.02 & 0.02 \\ 4 & 0.003 & 0.003 & 0.003 \\ 5 & 0.002 & 0.002 & 0.002 \\ 6 & 0.0085 & 0.008 & 0.008 \\ 7 & 0.02 & & 0.022\end{array}$

Table 3

Element taken

$0.0025 \mathrm{~g} \mathrm{ThO}_{2}$

$0.0025 \mathrm{~g} \mathrm{ZrO}_{2}$

$0.025 \mathrm{~g} \mathrm{~V}_{2} \mathrm{O}_{5}$

$0.2 \mathrm{~g} \mathrm{Fe}_{2} \mathrm{O}_{3}^{\dagger}$

$9.5 \mathrm{~g} \mathrm{Al}\left(\mathrm{NO}_{3}\right)_{3} \cdot 9 \mathrm{H}_{2} \mathrm{O}$
Amount extracted by $10 \mathrm{ml}$ of ethyl acetate

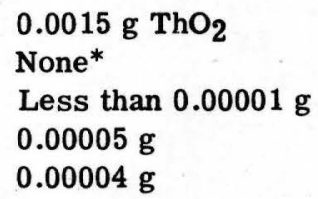

${ }^{*}$ Tested with phosphoric acid. No precipitate of zirconium phosphate formed after 2 days.

†This corresponds to about $1 \mathrm{~g}$ of the ferric nitrate used. The $0.05 \mathrm{mg}$ extracted is probably not the equilibrium value but the amount trapped in the ethyl acetate. 